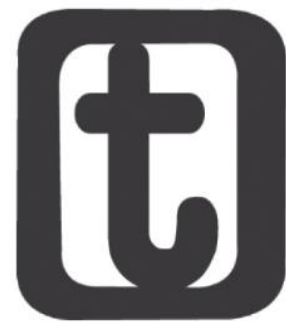

\section{CRISE DO CAPITAL, CONTRARREFORMA DA PREVIDÊNCIA SOCIAL E PANDEMIA}

\author{
Capital crisis, counter-reform of social security and pandemic
}

\author{
Priscila Semzezem* \\ https://orcid.org/0000-0002-5410-2585
}

Ana Maria Baima Cartaxo ${ }^{* * * *}$

https://orcid.org/0000-0002-4150-5342

\begin{abstract}
RESUMO
Este estudo bibliográfico e documental, de natureza qualitativa, objetiva discutir a situação dos trabalhadores/as brasileiros/as com a crise do capital agravado com a pandemia Coronavírus e a contrarreforma ${ }^{1}$ na previdência social. As proposições de estudos que tratam sobre a crise do capital em meio à pandemia do Coronavírus constituem-se em um campo de alta complexidade social, econômica, política e teórica. Na conjuntura brasileira se agrava ainda mais, pois, vivencia-se um momento de ataques brutais aos direitos sociais e trabalhistas conquistados historicamente. Destaca-se que todo esse processo vem afetando diretamente os trabalhadores e trabalhadoras em sua sobrevivência, desafiando estudiosos por respostas que subsidiem enfrentamentos. Em síntese, o estudo denuncia o agravamento das condições de vida da população e a fragilidade das políticas sociais, como a previdência social no enfrentamento a esse contexto. Por isso, a necessidade de pesquisas aprofundadas que possam contribuir no desvelamento das relações sociais constituídas, já que o pressuposto é assegurar os interesses do capital, ou seja, os lucros, em detrimento da vida.
\end{abstract}

\section{PALAVRAS-CHAVE}

Capitalismo. Pandemia. Contrarreformas. Previdência Social.

\section{ABSTRACT}

This qualitative bibliographic and documentary study aims to discuss the situation of Brazilian workers with the capital crisis aggravated by the Coronavirus pandemic and the counter-reform in social security. The proposals of studies that deal with the capital crisis in the middle of the Coronavirus pandemic constitute a

\footnotetext{
*Assistente Social. Mestra em Serviço Social e Política Social. Doutoranda em Serviço Social pela Universidade Federal de Santa Catarina. Professora titular da Universidade Estadual do Paraná/ Campus Paranavaí. (UEPR, Paranavaí, Brasil). Av. Gabriel Esperidião, s/no., Jd. Morumbi, Paranavaí (PR), CEP.: 87703-000. E-mail: priscilasemzezem@hotmail.com.

** Assistente Social. Doutora em Serviço Social. Professora aposentada da Universidade Federal de Santa Catarina e professora colaboradora do Programa de Pós-Graduação em Serviço Social (UFSC, Florianópolis, Brasil). R. Eng. Agronômico Andrei Cristian Ferreira, s/no, Trindade, Florianópolis (SC), CEP.: 88040-900. Email: anacartaxo@uol.com.br.
}

** DOI 10.22422/temporalis.2021v21n41p237-255

( $\mathrm{A}(\mathrm{s})$ Autora(s)/O(s) Autor(es). 2019 Acesso Aberto Esta obra está licenciada sob os termos da Licença Creative Commons Atribuição 4.0 Internacional (https://creativecommons.org/licenses/by/4.o/deed.pt BR), que permite copiar e redistribuir o material em qualquer suporte ou formato, bem como adaptar, transformar e criar a partir deste material para qualquer fim, mesmo que comercial. O licenciante não pode revogar estes direitos desde que você respeite os termos da licença.

${ }^{1}$ A categoria "contrarreforma" foi originalmente trabalhada pela Elaine Behring no livro: Brasil em contrareforma: a desestruturação do Estado e perda de direitos. São Paulo: Cortez, 2003.

Temporalis, Brasília (DF), ano 21, n. 41, p. 237-255, jan./jun. 2021. | ISSN 2238-1856 
field of high social, economic, political and theoretical complexity. In the Brazilian conjuncture it is even more aggravated, because it is experiencing a moment of brutal attacks on social and labor rights conquered historically. It is noteworthy that this whole process has been directly affecting men and women workers in their survival, challenging scholars for answers that support confrontations. In summary, the study denounces the worsening living conditions of the population and the fragility of social politics, such as social security in coping with this context. For this reason, the need for in-depth research that can contribute to the unveiling of established social relations, since the assumption is to ensure the interests of capital, that is, profits, to the detriment of life.

\section{KEYWORDS}

Capitalism. Pandemic. Counter-reforms. Social Security.

Submissão: 22/3/2021.

Aceito em: 11/6/2021.

\section{INTRODUÇÃO}

E ste estudo, a partir de uma pesquisa bibliográfica e documental de natureza qualitativa, tem por objetivo discutir a situação dos trabalhadores/as brasileiros/as com a crise do capital agravado com a pandemia Coronavírus e a contrarreforma na previdência social.

Considera-se que os ataques aos direitos dos/das trabalhadores/as brasileiros/as na última quadra histórica é integrante do pacote de estratégias para manutenção de lucros, em que o capital busca a superação de sua crise. São resultados concretos mais recentes desse projeto no Brasil: a contrarreforma da Previdência Social (EC n 103/12/11/2019), Lei da terceirização (Lei $n^{\circ}$ 13.429, de 2017), a Reforma Trabalhista (Lei $n^{\circ} 13.467$, de 2017), e a Emenda Constitucional 95/2017.

Além disso, tratar sobre o contexto atual é remeter ao que se desenha desde março de 2020, quando o mundo foi surpreendido por uma pandemia - Covid 19. O momento que se apresenta é de um cenário não apenas de crise sanitária, mas também política e com agravamento na economia. Todos esses elementos vêm atingindo diretamente trabalhadores e trabalhadoras em sua sobrevivência, e no caso brasileiro se acirra ainda mais, já que contraditoriamente os direitos sociais e trabalhistas historicamente conquistados estão sendo duramente destituídos. Dados indicam não só o número exacerbado de mortes pelo Coronavírus, mas também em conjunto o aprofundamento do desemprego, informalidade, precarização do trabalho e empobrecimento da classe trabalhadora.

A previdência social brasileira, nesse momento, constitui-se em uma política social importante de enfrentamento, pois, conforme afirma a Revista Seguridade Social e Tributação, n. 138 (2020, p. 7), é a “[...] maior política pública de distribuição de renda brasileira e patrimônio do trabalhador, responsável por $\mathrm{R} \$ 682,7$ bi do orçamento federal”. No entanto, vários ataques vêm sendo arquitetados e realizados desde a década de 1990, estando na mira do capital como uma de suas estratégias de superação da crise.

A necessidade de conhecer essa realidade e realizar denúncias é de extrema urgência para pressionar a garantia de um mínimo de civilidade em um contexto de crise do capital e pandemia do coronavírus. Tendo o entendimento de que ações, como por exemplo a luta para assegurar a política de previdência social não é capaz por si só de acabar com a relação 
de exploração presente no modelo capitalista de sociedade, exige a luta de todas/os trabalhadoras/es em prol de um outro projeto societário.

Este artigo está estruturado em dois itens, o primeiro - Elementos para compreensão da contrarreforma da previdência social brasileira - trata das razões da mesma destituindo o discurso oficial que ideologicamente cumpre o papel do consenso em prol da sua realização. O segundo item - A Pandemia e a Previdência Social - analisa a crise sanitária provocada pela COVID-19 no contexto do aguçamento da crise do sistema capitalista e os seus rebatimentos na Previdência Social.

Objetivamos, com este artigo, contribuir para análise da realidade atual brasileira no campo proposto - previdência e trabalho, no sentido de subsidiar estudos e reflexões aos pesquisadores e estudiosos em políticas sociais e, ainda possibilitar abertura de novas pesquisas que possam aprofundar o estudo que ora apresentamos.

\section{ELEMENTOS PARA COMPREENSÃO DA CONTRARREFORMA DA PREVIDÊNCIA SOCIAL BRASILEIRA}

O cenário atual requer estudos e pesquisas que subsidiem o enfrentamento à pandemia do coronavírus, mas é preciso ressaltar que esse é marcado também pela crise do capital. Parte-se do pressuposto que as crises do sistema capitalista são cíclicas, conforme já nos anunciou Mandel (1982), ocorrendo quando a queda da taxa média de lucro expressa o esgotamento de um padrão de acumulação e determina o estabelecimento de estratégias para sua restauração e expansão em outro padrão.

Após o esgotamento dos chamados anos dourados do capital, na década de 1970, desponta a atual crise que desde então vem buscando estratégias para sua superação, tais como a reestruturação produtiva por meio da alteração no processo de trabalho, a preponderância da financeirização, e a inserção da política neoliberal, cuja ação primordial é a valorização do mercado em detrimento das conquistas sociais. Em síntese, são táticas que atingem diretamente os direitos sociais e trabalhistas.

Para Mészáros (2013), a crise contemporânea do capital é ao mesmo tempo sistêmica e estrutural, por atingir um dos elos centrais do sistema capitalista, o trabalho, e ao mesmo tempo abranger todos os aspectos da vida humana, causando destruições em prol da sua continuidade. Desta forma na atualidade, as relações de trabalho são reconfiguradas e adequadas à reestruturação produtiva, acentuando a flexibilização e sua precarização, transforma a dinâmica da vida social e se desdobram na degradação da vida humana.

Os ataques aos direitos sociais e trabalhistas fundamentam-se na hegemonização do capital financeiro, na apropriação do fundo público (SALVADOR, 2010) e pela busca de novas formas de acumulação. Assim, o que antes eram considerados direitos, ou proteção social, assegurados pelo Estado, vêm se transformando em serviços vendidos no mercado. Granemann (2007), também afirma:

A resposta factível ao capital centralizado pelas finanças para a organização da força de trabalho é estender a lógica das finanças para a totalidade da vida social e conformar uma sociabilidade na qual as políticas sociais mínimas operadas pelo 
Estado sejam elementos de financeirização no cotidiano dos trabalhadores; aquilo que restar da contra-reforma do Estado, dos sistemas de proteção social e dos direitos do trabalho passará a ser validado na esfera da monetarização da vida(GRANEMANN, 2007, p. 58).

É no contexto de financeirização do capital que as propostas de ajustes das economias de vários países se fazem presente, ocorrendo por meio da indicação de reformas e ajustes, recomendadas por agências multilaterais, tais como Fundo Monetário Internacional, Banco Mundial, ou seja, instituições que representam os interesses da oligarquia das finanças (NETTO; BRAZ, 2012). Também afirma Granemann (2007, p. 60): “A ‘coincidência' da aplicação das contra-reformas, por sua vez, evidencia importante diretriz do grande capital para a sua reprodução: a urgência de novas 'mercadorias', negócios e espaços para a realização dos superlucros".

As contrarreformas² da previdência social no Brasil, iniciadas em 1990, mas não só elas, são respostas concretas da manifestação desse processo de apropriação do capital aos direitos sociais e proteção social em busca da superação de sua crise. No ano de 1994, por exemplo, o Banco Mundial publicou um documento Prevenir a crise do envelhecimento: políticas para proteger as pessoas idosas e promover o crescimento, em que orienta as contrarreformas da previdência social em todo mundo (GRANEMANN, 2007).

Em 2005, outro documento foi publicado por dois diretores do Banco Mundial sobre as "Reformas previdenciárias e apontamentos para o futuro". Granemann (2007, p. 62) aponta que o documento indicou: "[...] o argumento central não sofreu modificações em relação ao de 1994: continua a ser imprescindível reformar os sistemas públicos de previdência".

$\mathrm{Na}$ esteira desse processo, em 2017, o Banco Mundial realizou outros estudos que resultaram na publicação do documento intitulado Um ajuste justo: Análise da eficiência e equidade do gasto público no Brasil, o argumento é centrado na necessidade de colocar as contas fiscais do Brasil de volta a uma trajetória sustentável, pois "[...] o gasto tornou-se cada vez mais engessado pela rigidez constitucional em categorias como folha de pagamento e previdência social, deixando quase nenhum espaço para despesas discricionárias e de investimento" (GRUPO BANCO MUNDIAL, 2017, p. 1).

A realidade concreta demonstra que o Brasil vem adotando as orientações dos representantes das oligarquias das finanças sem objeções. Segundo a ANFIP (ASSOCIAÇÃO NACIONAL DOS AUDITORES-FISCAIS DA RECEITA FEDERAL DO BRASIL; FUNDAÇÃO ANFIP DE ESTUDOS TRIBUTÁRIOS E DA SEGURIDADE SOCIAL, 2020), desde 2015, não só a previdência social, mas o conjunto dos direitos sociais e trabalhistas no Brasil vêm sofrendo duros ataques, tais como cortes em orçamentos, políticas e programas modificados, mudanças nas legislações, entre outras, com a justificativa de que as políticas sociais oneram os cofres públicos. Conforme a ANFIP (ASSOCIAÇÃO NACIONAL DOS AUDITORESFISCAIS DA RECEITA FEDERAL DO BRASIL; FUNDAÇÃO ANFIP DE ESTUDOS TRIBUTÁRIOS E DA SEGURIDADE SOCIAL, 2020) com a EC 95- teto de gastos, inviabilizam-se os direitos sociais existentes, pois

\footnotetext{
${ }^{2}$ Convém lembrar que as contrarreformas previdenciárias se sucedem desde a década de 1990: EC nº 20 de 15/12/1998; EC n 40/ 29/05/2003; EC 41/ 19/12/2003 e EC 47/ 05/07/2005.
}

Temporalis, Brasília (DF), ano 21, n. 41, p. 237-255, jan./jun. 2021. | ISSN 2238-1856 
[...] o governo passou a desconstruir os mais diversos instrumentos públicos para a recuperação da economia e das empresas, inclusive o crédito. E, por meio de outros mecanismos, contribuiu para reduzir a renda das famílias, com precarização do emprego e das ocupações (e a consequente diminuição da renda do trabalho) e com muitas restrições para acesso aos programas sociais, mesmo diante do aumento do desemprego e do subemprego (ASSOCIAÇÃO NACIONAL DOS AUDITORES-FISCAIS DA RECEITA FEDERAL DO BRASIL; FUNDAÇÃO ANFIP DE ESTUDOS TRIBUTÁRIOS E DA SEGURIDADE SOCIAL, 2020, p. 77).

Outro elemento que rebateu diretamente na sobrevivência de trabalhadores/as brasileiros/as foi a Contrarreforma Trabalhista que:

Extinguiu e flexibilizou direitos, buscou inibir a associação classista, mas não gerou empregos. E, igualmente nocivo, contribuiu para precarizar as contas da previdência social. O texto final foi uma síntese de pretensões do setor empresarial. Legalizou e regrou várias formas de contratação para reduzir os custos para as empresas a partir da supressão de direitos e garantias dos trabalhadores. Facilitou as demissões e diminuiu as garantias de quitação dos débitos trabalhistas. Não bastasse isso, alterou diversas disposições que, direta ou indiretamente, atuavam na proteção da saúde do trabalhador. A legislação criada pela reforma, além de desconstruir direitos legalmente estabelecidos, promoveu alterações que visaram descontruir acórdãos e entendimentos já pacificados na Justiça do Trabalho. Trata-se de um amplo conjunto de medidas desestruturantes de direitos e de garantias (ASSOCIAÇÃO NACIONAL DOS AUDITORES-FISCAIS DA RECEITA FEDERAL DO BRASIL; FUNDAÇÃO ANFIP DE ESTUDOS TRIBUTÁRIOS E DA SEGURIDADE SOCIAL, 2020, p. 77).

Já a contrarreforma da Previdência Social (EC n 103/12/11/2019), conforme explica Gentil (2020), seis pontos possuem interferência direta na vida de trabalhadores e trabalhadoras brasileiras:

1.Idade e contribuição para homens e mulheres:

A idade de aposentadoria para os trabalhadores urbanos do RGPS manteve-se a mesma para os homens ( 65 anos), mas o tempo de contribuição subiu de 15 para 20 anos. No caso das mulheres, a idade é que subiu, passando de 60 para 62 anos, mas o tempo de contribuição permaneceu o mesmo (15 anos). Essas duas mudanças de parâmetro vão inviabilizar a aposentadoria de milhares de trabalhadores urbanos, porque as condições da estrutura ocupacional (mais deteriorada pela reforma trabalhista e pela recessão) definem a capacidade de contribuir e, portanto, de se aposentar (GENTIL, 2020, 434).

\section{Aposentadoria para professores:}

Os professores da educação infantil e do ensino fundamental e médio passarão a ter que cumprir o requisito de idade mínima - 60 anos, para os homens e 57 anos, para mulheres, além do tempo de contribuição de 25 anos, para ambos. Na regra anterior era exigido apenas tempo de contribuição de 30 anos, para os homens e 25 anos, para mulheres, sem a imposição da idade mínima. Essas mudanças nos parâmetros vão dificultar a aposentadoria de milhares de professores por exigir maior tempo de permanência no mercado de trabalho (GENTIL, 2020, p. 436).

\section{Perda no valor mensal das aposentadorias do RGPS:}


A drástica redução das aposentadorias ocorrerá por dois motivos. Primeiro, porque, na regra anterior, o salário de benefício era calculado com base na média dos $80 \%$ maiores salários de contribuição, possibilitando o descarte dos $20 \%$ menores salários. Pela nova regra de cálculo do valor da aposentadoria se utilizará a média aritmética simples de $100 \%$ dos salários de contribuição, sem exclusão dos menores salários, o que puxará o valor médio para baixo. A média não poderá ultrapassar o teto do RGPS. Segundo, o valor da aposentadoria será menor porque corresponderá a $60 \%$ daquela média (na regra anterior esse percentual era de $85 \%$ ). Haverá um acréscimo de $2 \%$ para cada ano de contribuição que exceder o tempo de 20 anos de contribuição, para os homens e, de 15 anos de contribuição, para as mulheres filiadas ao RGPS (GENTIL, 2020, p. 437).

\section{Privatização dos benefícios:}

O texto da reforma permite a privatização de todos os benefícios não programados, como auxílio doença, acidente de trabalho e salário maternidade, após aprovação de lei complementar. O INSS terá exclusividade apenas sobre as aposentadorias e parte das pensões (GENTIL, 2020, p. 437-438).

5. Queda na pensão por morte: “A pensão por morte passará por queda significativa de valor, prejudicando de forma injustificável viúvas e viúvos” (GENTIL, 2020, p. 438).

\section{Implicações nas aposentadorias especiais:}

As aposentadorias especiais foram severamente atingidas. Têm direito a aposentadoria especial os que trabalham expostos a agentes nocivos químicos, físicos, biológicos ou a associação de agentes prejudiciais à saúde ou a integridade física, fazendo com que as pessoas venham a morrer prematuramente. Na regra anterior, não era necessário cumprir com o requisito da idade mínima para ter direito ao benefício. A concessão dependia apenas da comprovação de 15, 20 ou 25 anos de tempo de trabalho permanente. A reforma inseriu no seu texto a dupla exigência de idade mínima, de 55, 58 ou 60 anos, a depender do tempo de exposição máximo a agentes nocivos, e o tempo de atividade de 15, 20 ou 25 anos, até que lei complementar seja publicada (GENTIL, 2020, p. 438-439).

Gentil (2020) também destaca que todas essas mudanças foram “construídas” pois fazem parte de um "pacote" de ações:

A forte desaceleração (iniciada em 2014 com reflexos até os dias atuais) e a reforma trabalhista (aprovada em $2017 \mathrm{com}$ a lei 13.467) produziram enorme desemprego, terceirização da força de trabalho e informalidade, contribuindo para achatar as receitas da previdência e favorecer o discurso de desmonte do sistema público alardeado pelo governo de ultradireita que chegou ao poder em 2019 (GENTIL, 2020, p. 431-432).

Nesse sentido, a contrarreforma da previdência é sustentada pelos organismos multilaterais através de um discurso impetrado de que ela irá propiciar o crescimento econômico, a justificativa, conforme apontam Lourenço, Lacaz e Goulart (2017, p. 481): "[...] está calcada no mito do seu déficit".

Analisando os Gráficos 1 e 2, que tratam do orçamento da União entre os anos 2011 e 2020, é possível identificar, primeiro que o orçamento federal executado entre os anos de $2011 \mathrm{e}$ 2020 aumentaram. Seguindo o mesmo caminho, ao tratar especificamente a comparação 
entre os dados do pagamento da dívida, esta aumentou consideravelmente. Já em relação à previdência social a porcentagem investida diminuiu.

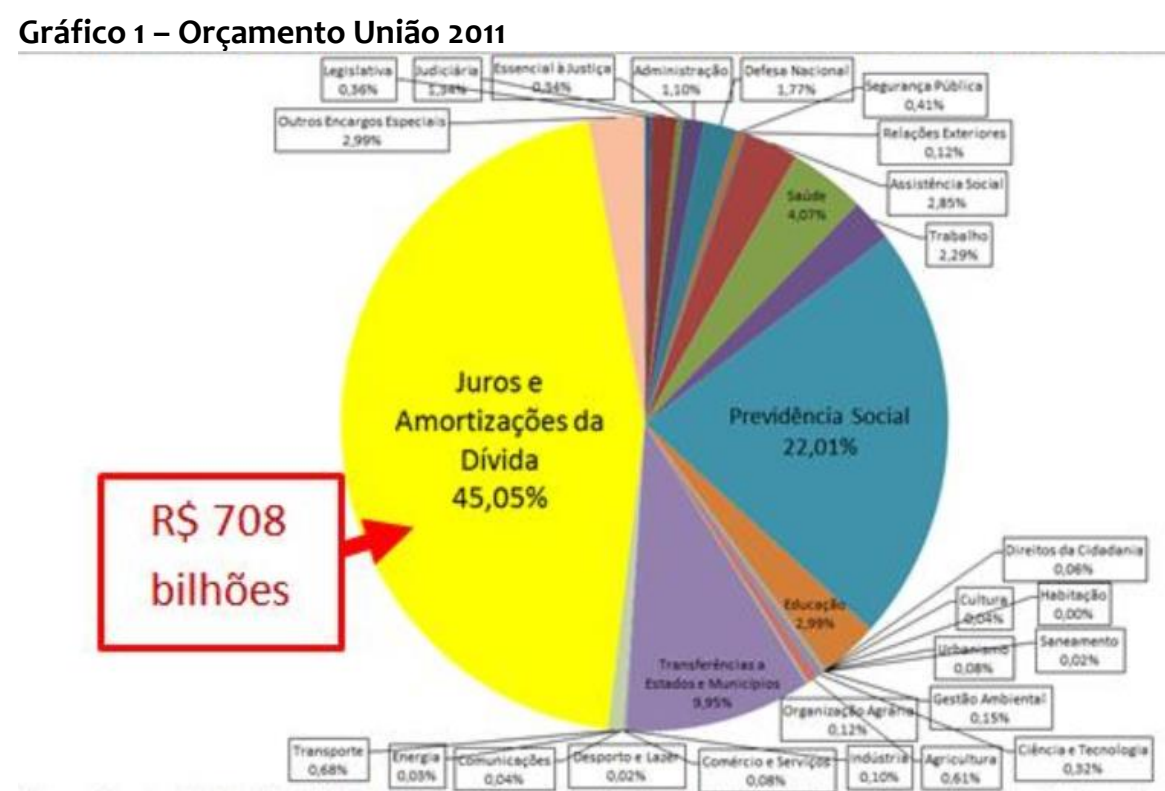

Fonte: Auditoria Cidadã da Dívida Pública (2020).

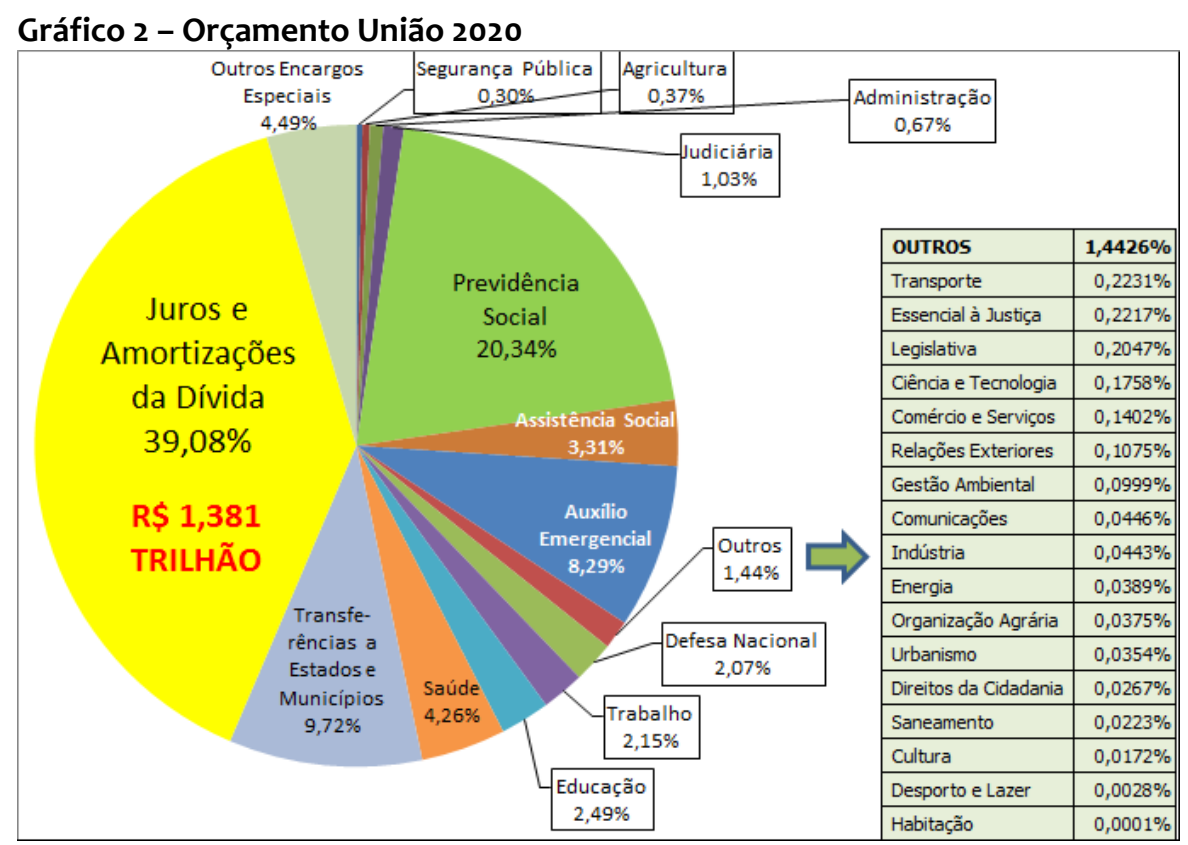

Fonte: Fatorelli, Ávila e Muller (2021, não paginado).

Nesse sentido, ao tratar sobre o mito do déficit da previdência no Brasil é equivocado, pois, é possível observar que a maior parte do orçamento está sendo destinado para o pagamento da dívida, ou seja, para enriquecer corporações financeiras, em detrimento de investimentos em aspectos que impactam diretamente a vida da população brasileira, como por exemplo a seguridade social. Gentil (2019) também destaca, a partir de um estudo coerente dos dados, que o nó fiscal em que passa o contexto brasileiro, possui como justificativa os juros que beneficiam fundos especulativos, bancos, corporações não financeiras e pessoas com elevado nível de renda. 
Desta forma, o ajuste fiscal tem como finalidade maior investimento para o capital em detrimento ao social. Sendo comprovado quando analisado o orçamento da seguridade social, identifica-se que vem sendo esvaziado para atender os interesses do capital:

O governo federal vem promovendo um desmonte nas receitas da seguridade social que advém das medidas tomadas pelo governo brasileiro por meio das renúncias tributárias para socorrer o capital, com graves implicações sobre o financiamento da seguridade social. Destacam-se, sobretudo, às políticas de desonerações tributárias das contribuições sociais e a desoneração da folha de pagamento, que afetam o financiamento do orçamento da seguridade social (SALVADOR, 2019, p. 112)

Dados da ANFIP (ASSOCIAÇÃO NACIONAL DOS AUDITORES-FISCAIS DA RECEITA FEDERAL DO BRASIL; FUNDAÇÃO ANFIP DE ESTUDOS TRIBUTÁRIOS E DA SEGURIDADE SOCIAL, 2020) também demonstram de forma concreta e direta o desmonte da seguridade social por meio da DRU- Desvinculação de Receitas da União:

\begin{abstract}
A DRU, sob as mais diversas denominações, vem desde 1994, subtraindo recursos para desmontar o aspecto superavitário do Orçamento da Seguridade Social. Esse sempre foi o principal alvo da desvinculação. Essa subtração de recursos da Seguridade passou de uma média de $R \$ 62,7$ bilhões, entre 2013 e 2015, para R\$ 99,2 bilhões, em 2016, R\$ 113,3 bilhões, em 2017 e R\$ 120,1 bilhões, em 2018. Em 2019, foram R\$ 116,6 bilhões ASSOCIAÇÃO NACIONAL DOS AUDITORES-FISCAIS DA RECEITA FEDERAL DO BRASIL; FUNDAÇÃO ANFIP DE ESTUDOS TRIBUTÁRIOS E DA SEGURIDADE SOCIAL 2020, p. 32). ${ }^{3}$
\end{abstract}

Em síntese, o déficit da previdência vem sendo utilizado por 28 anos como justificativa para contrarreformas. Estudos realizados por Salvador (2017) apontam também as investidas que o OSS sofre para que seja desmontado:

\footnotetext{
O governo federal inclui no OSS tanto na Lei Orçamentária Anual (LOA), como nos resultados divulgados pela STN, todas as despesas previdenciárias tanto do RGPS, como as do Regime Próprio de Previdência (RPP) do setor público, além de despesas com benefícios dos servidores públicos federais e os gastos com saúde dos militares. Esses gastos (acertadamente) não são considerados nos resultados apurados pela Anfip. A instituição inclui no montante das receitas os valores desviados pela DRU, o que resultaria em um OSS superavitário bem diferente das contas oficiais. Assim, o chamado OSS, na contabilidade oficial, está inflado por despesas que deveriam ser do orçamento fiscal e está também subestimado nas receitas, pois não considera os valores desviados pela DRU e pelas renúncias tributárias (SALVADOR, 2017, p. 432).
}

Este cenário demonstra que o processo orientado pelo Banco Mundial possui um direcionamento político de suas ações voltado para a defesa do projeto capitalista de sociedade, confirmando a tese de ser um processo político e ideológico e "[...] limita o papel do Estado na área social, criando as condições e a estrutura necessárias para que o capital explore financeiramente as políticas sociais, em especial a da PS" (LOURENÇO; LACAZ; GOULART, 2017, p. 479).

Nesse sentido, a chamada crise fiscal, utilizada como justificativa ideológica para os processos de contrarreforma não é uma característica nacional, ela se torna um apelo utilizado pelo capital mundial cujo objetivo é aumentar as taxas de acumulação e para isso

\footnotetext{
${ }^{3}$ A DRU foi extinta com a EC 103/ 2019
} 
vários argumentos são utilizados, tais como: baixo crescimento econômico, desemprego, queda de arrecadação e desequilíbrio nas contas públicas (LOURENÇO; LACAZ; GOULART, 2017).

Mota e Tavares (2016) também explicam que o Estado se constitui como instrumento importante de legitimação desse processo, pois, cria e legaliza o aparato jurídico das formas de exploração do trabalho, assegurando condições favoráveis à acumulação:

[...] a principal mediação da precarização do trabalho e dos trabalhadores tem origem na atuação do Estado, seja por meio da legislação trabalhista, dos sistemas de proteção social ao trabalhador (saúde e previdência social), seja da incorporação de diferentes estatutos jurídicos do trabalho ou da sua inexistência, no conjunto de experiências e regras socialmente aceitas (MOTA; TAVARES, 2016, p. 234).

O processo de privatização dos serviços resulta na redução do salário nominal do trabalhador, ou seja, quando se privatizam e/ou reduzem políticas, benefícios e direitos repercutem diretamente na sobrevivência dos trabalhadores/trabalhadoras (MOTA; TAVARES, 2016).

As autoras ainda destacam que o pacote de estratégias para manutenção da taxa de acumulação capitalista também ocorre por meio de ações para desvalorização da força de trabalho com:

1. a violação do valor do trabalho socialmente necessário, através da redução dos salários/remuneração do trabalhador, restringindo sua reprodução e a da sua família aos mínimos de sobrevivência, portanto abaixo dos "padrões normais" socialmente vigentes em cada sociedade (materiais, culturais e morais), porém mantendo a sua dependência do mercado para consumir seus meios de sobrevivência; 2) a redução da qualidade do tempo real de vida do trabalhador pelo desgaste psicofísico do trabalho e pela privatização dos serviços públicos; 3 ) o sitiamento de qualquer projeto de vida do trabalhador e sua família (ético, político, pessoal, social), empobrecendo suas objetivações e ideários, dados a centralidade da luta pela sobrevivência, a insegurança, as incertezas e os riscos do trabalho (MOTA; TAVARES, 2016, p. 242).

O/A trabalhador/a, nesse contexto, explicam as autoras, passa a ser o único e responsável pela sua reprodução, e as necessidades essenciais da vida passam a ser mercadorias. $O$ acesso ou não, irá depender da venda de sua força de trabalho, portanto, assegura um nicho de mercado altamente lucrativo, pois, os serviços devem ser adquiridos por trabalhadores e trabalhadoras "[...] mediante a compra com parte de seus pífios salários" (MOTA; TAVARES, 2016, p. 246).

Desta forma, segundo Lara e Maranhão (2019), os direitos sociais, entre eles, a previdência social, transformados em mercadorias ingressam no processo de valorização e destacam: "[...] as privatizações, as contrarreformas nas políticas sociais, são fenômenos de um mesmo processo socioeconômico que demonstra a crise generalizada e duradoura da produção e reprodução social capitalista" (LARA; MARANHÃO, 2019, p. 56-57).

Lourenço, Lacaz e Goulart (2017) explicam que esse processo tem vários desdobramentos e propiciam vários desafios à classe trabalhadora, pois, inclusive são criadas estratégias 
ideológicas dos trabalhadores que acabam formatando o pensamento para aceitar as contrarreformas, entre elas, nesse contexto a da previdência social.

Há uma inserção de fatores materiais, sociais e políticos levando-os a acreditar que a melhor forma é de oferta dos serviços sociais pela via do mercado, para isso, realizam diversas ações de precarização, ao ponto de que a dependência significa risco, insegurança e medo. Assim, os trabalhadores divididos arcam em conjunto com as empresas onde trabalham: planos de saúde, convênios médicos, escolas particulares, previdência privada.

Diante disso, compreender as falácias que envolvem esse discurso é de extrema urgência e necessidade, inclusive para orientar as pautas de lutas coletivas. Em seguida será contextualizado o agravamento da situação em decorrência da crise sanitária pandêmica do Coronavírus que aguça a situação já crítica econômica, social e política brasileira.

\section{A PANDEMIA E O CONTEXTO DA PREVIDÊNCIA SOCIAL}

A crise sanitária, explicitada pela Covid -19, despontou a partir da China em novembro de 2019 e tem se disseminado pelo mundo desde março de 2020. Em meio a esse contexto, o Brasil vem se destacando, atualmente é vice-campeão em mortes, perdendo apenas para os EUA. O país contabiliza, atualmente, 18.054.653 casos confirmados e 504.717 óbitos (CORONAVÍRUS/BRASIL, 2021).

O quadro geral do capitalismo mundial e, de forma particular, a situação brasileira contraria a ideia de que o vírus seja apenas originado da natureza. Harvey (2020) ao discutir que a mesma deve ser pensada em sua conexão com a cultura, a economia e vida cotidiana, adverte que o capital ao interferir nas situações ambientais, modifica as suas condições. Dessa maneira "[...] Os vírus sofrem mutações o tempo todo para ter certeza. Mas as circunstâncias em que uma mutação se torna ameaçadora e fatal dependem das ações humanas". "[...] os impactos econômicos e demográficos da propagação do vírus dependem de fendas e vulnerabilidades preexistentes no modelo econômico hegemônico" (HARVEY, 2020, não paginado).

A posição do governo brasileiro frente à pandemia com negacionismo da doença, da ciência e dos cientistas, subestimando a voracidade do vírus e da situação grave e de penúria da população brasileira, que padece da doença ou se encontra enlutada, retardou por tempo insuportável o enfrentamento da pandemia - quer o auxílio emergencial aos mais desfavorecidos, no momento à deriva, como no seu combate sanitário propriamente dito. Seguiu o descaso do modelo trumpista. A consequência que estamos vivenciando pelas estatísticas oficiais nos coloca junto a esse primeiro modelo estadunidense do desastre. Ao lado disso, o governo brasileiro na perseguição mimética desse império continua no desenfreado ajuste econômico do Guedes. Destarte, o governo vetou 58 itens da Lei de Diretrizes Orçamentária - 2021, que proibia o não contingenciamento das despesas. Entre elas, a compra de vacinas contra o coronavírus ${ }^{4}$.

O Executivo apontou ainda que a inclusão de despesas não passíveis de contingenciamento contribui para a elevação da rigidez do Orçamento, dificultando não apenas o cumprimento da meta fiscal, como a observância do teto de gastos e da regra de ouro.

\footnotetext{
${ }^{4}$ Senado Notícias (LDO..., 2021) o presidente depois se retratou.
} 
O governo alegou que o não cumprimento dessas regras fiscais, ou mesmo a mera existência de risco de não cumprimento, poderia provocar "insegurança jurídica e impactos econômicos adversos para o país, como a elevação de taxas de juros, a inibição de investimentos externos e a elevação do endividamento" (LDO..., 2021, não paginado).

A falácia de que a pandemia democraticamente atinge a todos independente de sua classe, não se sustenta. Harvey (2020, não paginado) considera que a situação epidêmica da cólera no século XIX não se aplica na realidade atual. "Os impactos econômicos e sociais são filtrados através de discriminações 'costumeiras' que estão em toda parte em evidência”. Antunes (2020) descreve que o vírus teve a maior expansão nas trabalhadoras brancas do que nos homens brancos, sendo ainda mais cruel com as negras do que com as brancas. $\mathrm{E}$ se acentua mais veementemente com relação às indígenas, imigrantes e refugiadas. Isso em razão da precariedade em que vive a população brasileira: desemprego, informalidade, desalento, trabalhos intermitentes, uberizados e demais formas instáveis de sua realização. Estes são propícios a uma maior contaminação, considerando as frágeis condições de suas vidas e saúde. Na pandemia estão impossibilitados de isolamento em razão das suas circunstâncias habitacionais e necessidade de busca de alguma forma de trabalho para sobreviver. Ao lado disso, contam com a deficiência da saúde pública que vem sendo paulatinamente desconstruída em sua proposta Constitucional. Antunes (2020) considera que

A classe trabalhadora, então, se encontra sob intenso fogo cruzado. Entre a situação famélica e a contaminação virótica, ambas empurrando para a mortalidade e a letalidade. Tal vilipêndio se acentua ininterruptamente pela autocracia de Bolsonaro e pela pragmática neoliberal primitiva e antissocial de Guedes (ANTUNES, 2020, p. 10-11).

As consequências dessa combinação de crise capitalista e sanitária é o agravamento da desigualdade (OXFAM, 2021). Segundo esse relatório, houve um aumento da riqueza dos 10 maiores bilionários desde o começo da crise virótica. Esse montante seria suficiente para evitar que as pessoas mergulhassem na pobreza em decorrência da COVID-19. Paradoxalmente, quase metade da população mundial sobrevive com menos de US\$ 5,50 por dia. Em 40 anos, 1\% mais rico ganhou mais do que o dobro da renda da metade mais pobre da população do planeta (OXFAM, 2021). Nos EUA aproximadamente 22 mil latinos e latinas e pessoas negras poderiam estar vivas em fins de 2020 se os índices de mortalidade fossem semelhantes aos das pessoas brancas (OXFAM, 2020).

No mundo, a pandemia dilacerou mais de dois milhões de vidas e empurrou centenas para a miséria absoluta. No Brasil, as pessoas negras têm 40 \% mais probabilidade de morrer desse vírus do que as brancas.

Um mundo em que o $1 \%$ mais rico consumiu duas vezes mais carbono que os $50 \%$ mais pobres no último quarto de século, levando à destruição do clima. Um mundo em que o fosso crescente entre ricos e pobres aumentou e exacerbou as históricas desigualdades de gênero e raça (OXFAM, 2021, p.11).

Ao escancarar o profundo abismo entre ricos e pobres, a pandemia demonstrou a degradação e subfinanciamento do sistema público de saúde ao lado da deficiência do privado. Além disso, teve impacto profundo na educação, quando mais de 180 países 
tiveram que fechar temporariamente as escolas, atingindo aproximadamente 1.700 bilhão de crianças. Nos países pobres a situação foi ainda mais grave (OXFAM, 2021). No trabalho centenas perderam seus empregos. No Brasil a taxa de desocupação atingiu 14,7\%, ou seja, 14,8 milhões de pessoas; em relação ao número dos trabalhadores sem carteira assinada, foi de 9,7 milhões, já a taxa de informalidade chegou a 39,6\% da população ocupada, o que representa 34 milhões de trabalhadores informais no país no primeiro trimestre de 2021 (BARROS, 2021).

Essa situação denuncia a realidade brasileira de pobreza em que se encontra a população. Em 2019, 10\% de pessoas com menores rendimentos domiciliares per capita percebiam uma parcela de $0,8 \%$ do total de rendas, enquanto os $10 \%$ com maiores rendimentos abarcam $42,9 \%$ do total recebido pelas pessoas (IBGE, 2020, p. 50). O índice de Gini confirma esse empobrecimento ao demonstrar que o rendimento domiciliar per capita do Brasil foi de 0,543, apresentando aumento em relação a 2012 (0,540). A desigualdade entre as grandes regiões brasileiras mostra essa permanência, em que o Sul tem a menor desigualdade de rendimentos (0,467 em 2019), em paradoxo com o Nordeste, cujo Gini foi de 0,559 em 2019 (IBGE, 2020, p.52). Sem o auxílio emergencial desde janeiro de 2021,5 a situação de pobreza tende a piorar. Foram investidos $\mathrm{R} \$ 260$ bilhões abrangendo 67,8 milhões de pessoas ${ }^{6}$. Segundo Lima (2021), 20 milhões de pessoas estão vivendo em extrema vulnerabilidade. Estudos realizados pela Tendência Consultoria Integrada (SEM AUXÍLIO..., 2021) apontam que as classes $D$ e $E$ devem perder quase $1 / 4$ da renda disponível. $E$ conclui que $R \$ 48$ bilhões deixarão de ser movimentados entre os mais pobres.

A fome grassa mundialmente milhares de pessoas de forma acentuada a partir da pandemia, conforme nos informa OXFAM (2020). Segundo o relatório dessa entidade a estimativa em 2019 era de 821 milhões de pessoas com insegurança alimentar (OXFAM, 2020). Os dez países com o índice mais alto de fome abrangem $65 \%$ do planeta7. Enquanto isso, as oito maiores empresas alimentícias e de bebidas mundiais pagaram US \$18 bilhões para seus acionistas no início da pandemia, eficaz para resolver o problema, de acordo com esse mesmo relatório. Ao contrário, novos países ingressaram nessa lista - Índia, África do Sul e Brasil. Este último, em 2018, aumentou em 100 mil (para 5,2 milhões) o número de pessoas com fome (OXFAM, 2020). Em razão do desemprego, conforme já noticiado, cortes radicais nas políticas sociais por meio dos pacotes de austeridade com o desmantelamento das políticas de proteção social - trabalho e previdência, o que se agravou com a situação pandêmica da COVID-19, dilatando a pobreza e a fome.

É no momento de crise, e, ainda com a atual pandemia provocada pela COVID-19, que há uma maior demanda à política previdenciária, quer pelo aumento de doenças e acidentes de trabalho devido às precárias condições de vida e trabalho da população pobre, como pela busca de algum benefício, que muitas vezes se constituem como formas estratégicas de sobrevivência ${ }^{8}$. Ao mesmo tempo acontece a desconstrução sistemática e em grau

\footnotetext{
${ }^{5} \mathrm{~A}$ última parcel do auxílio emergencial de 2020 ocorreu em dezembro. Suspenso retornou em 2021 a partir de abril de 2021 , a ser pago em quatro parcelas incialmente, mas no momento estendido até outubro de 2021, com valores inferiores ao ano anterior, de $\mathrm{R} \$ 150,00, \mathrm{R} \$ 250$, e $\mathrm{R} \$ 375$ ( Magno, 2021).

${ }^{6}$ As parcelas do auxílio emergencial foram de: $\mathrm{R} \$ 300,00, \mathrm{R} \$ 600,00$ e $\mathrm{R} \$ 1200,00$ (DALL’AGNOL, 2020).

7“[...]lêmen, República democrática do Congo (RDC), Afeganistão, Venezuela, região do Sahel da África Ocidental, Etiópia , Sudão, Sudão do Sul, Síria e Haiti" (OXFAM, 2020, p. 2).

${ }^{8}$ Sobre o assunto consultar: CARTAXO, Ana Maria Baima. Estratégias de Sobrevivência: a previdência e o serviço Social. 2. ed. São Paulo: Cortez, 2008.
} 
crescente dessa política pelas razões já apresentadas- ajustes, contrarreformas. E ainda, por meios infraconstitucionais - Medidas Provisórias, Decretos, Portarias e outros atos gerenciais que muitas vezes contrariam a própria Lei maior. Esse conjunto de fatores, aliados às condições instáveis de trabalho, dificulta ou impede o acesso aos direitos previdenciários. O Quadro 1 possibilita visualizar o movimento quantitativo de concessão de benefícios e expressa também o alto índice de indeferimento, no período de 2016 a 2020.

Quadro 1. Benefícios concedidos e indeferidos - 2016- 05/2020

\begin{tabular}{|l|l|l|}
\hline ANOS & CONCEDIDOS & INDEFERIDOS \\
\hline 2016 & 5.132 .451 & 4.164 .435 \\
\hline 2017 & 4.995623 & 3.950436 \\
\hline 2018 & 5.123 .777 & 3.889600 \\
\hline 2019 & 5.190239 & 4.201320 \\
\hline $\left.2020{ }^{*}\right)$ & 1.870 .382 & 1.815 .216 \\
\hline
\end{tabular}

Fonte: Construído a partir do Boletim Estatístico da Previdência Social - Ministério da Economia - Secretaria de Previdência Social - Coordenadoria Geral de Estatística, Geografia e Atuária, v.25, n.5, maio 2020.

( ${ }^{*}$ Os dados correspondem aos meses de janeiro a maio de 2020. Não encontramos estatística, nessa fonte, a respeito do ano de 2020. Mas conforme Lorran (2021, não paginado) o INSS “[...] negou mais de 4,465 milhões de pedidos de benefício ao longo do ano passado. Esse é o maior número de indeferimentos para um ano desde, pelo menos, 2006)".

Destacamos como aprofundamento da destituição de direitos a MP 871/2019, convertida na Lei $n^{\circ}$ 13.846- 19/06/ 2019, que estabeleceu o Programa Especial para Análise de Benefícios com Indícios de Irregularidades (SINDICATO DOS SERVIDORES E TRABALHADORES PÚBLICOS EM SAÚDE, PREVIDÊNCIA E ASSISTÊNCIA SOCIAL NO ESTADO DE SÃO PAULO, 2020). Isso significou restringir direitos, cujo fundamento é a busca de fraudes, o que costumeiramente o governo tem realizado em grande proporção com os benefícios por incapacidade, o chamado "[...] pente-fino do INSS" (PENTE-FINO..., 2019). Além disso, limitou o pagamento de auxílio-reclusão apenas aos detidos em regime fechado. Ao mesmo tempo em que vetou o acesso do INSS às informações de empresas e segurados na Receita Federal. Mas continuam crescendo as renúncias em relação às contribuições sociais. A arrecadação do CONFINS sofreu uma queda de R\$251,5 bilhões (2018) para $\mathrm{R} \$ 238,6$ bilhões (2019). O aumento das renúncias passou de $\mathrm{R} \$ 67.2$ bilhões (2018) para R\$70,2 bilhões (2019) (ASSOCIAÇÃO NACIONAL DOS AUDITORES-FISCAIS DA RECEITA FEDERAL DO BRASIL; FUNDAÇÃO ANFIP DE ESTUDOS TRIBUTÁRIOS E DA SEGURIDADE SOCIAL, 2020, p. 21).

Enquanto isso, o INSS notifica para revisão 1,7 milhão de benefícios. "Em meados de setembro, mais de 1,5 milhão estava na fila de espera para dar entrada nos seus benefícios Pelo menos metade $(50,4 \%)$ precisava, necessariamente, de atendimento presencial" (CAVALLINI, 2020, não paginado). "Em 2019, 261,3 mil benefícios foram cancelados ou suspensos, perfazendo uma economia mensal estimada na ordem de 336 milhões de reais e, prevista em um ano, na ordem de 4,3 bilhões de reais" (INSS..., 2019, não paginado). 
Ao lado disso, o desmantelo estrutural da entidade institucional Instituto Nacional de Seguro Social (INSS) - com a maior burocratização e logística, tem sido empecilhos a mais ao acesso das/dos seguradas/os aos seus direitos. Isto porque desde a implantação do INSS - Digital a população pobre tem tido dificuldade de agendar seus requerimentos, quer pela falta de equipamento de informática como pela deficiência de conhecimento, tratando-se de um contingente populacional de baixo poder aquisitivo, escolaridade e compreensão das técnicas digitais.

A questão que se coloca é: o que a pandemia COVID-19 tem a ver com a contrarreforma da previdência social? A resposta é complexa, mas é possível apontar que a contrarreforma da previdência social está entre as ações que diminuíram a capacidade de enfrentamento das sequelas produzidas no contexto da pandemia, em detrimento do fortalecimento do capital. Desta forma, ao invés dos direitos sociais serem preservados em virtude de mínimo de civilidade à população, estes estão sendo duramente atacados. A contradição desse processo é, conforme Netto e Braz (2012), o capital é vitorioso em todas as partes, a competitividade e o mercado se fazem presentes.

\section{CONSIDERAÇÕES FINAIS}

Este estudo considera que na atualidade os processos estão em um campo contraditório, várias ações apresentam-se em defesa dos trabalhadores, travestidos na luta pelos direitos, mas, na essência não fazem mais do que a reprodução ampliada do capital e Favaro (2017) chama a atenção em "[...] Uma tendência dos discursos e ações atuais é combater os efeitos da sociabilidade do capital, como desigualdade social, a miséria, a violência, mas sem apreender as suas causas" (FAVARO, 2017, p. 34).

Neste sentido, o atual contexto nos tensiona, o fato é que, na relação do capital, "[...] os métodos de produção do mais-valor são, simultaneamente, métodos da acumulação, e toda expansão da acumulação se torna, em contrapartida, um meio para o desenvolvimento desses métodos[...]" (MARX, 2017, p. 720), resultando no fato de que "[...] a situação do trabalhador, qualquer que seja seu pagamento, alto ou baixo, tem de piorar" (MARX, 2017, p. 720-721).

Isso significa que a crise do capital, para a sua recuperação, utiliza-se de estratégias para manutenção da taxa de lucro que atinge as condições de trabalho e de vida de trabalhadores e trabalhadoras. O Estado é determinante para legitimar esse processo juridicamente, por meio das leis e assegurar o desenvolvimento do capital, e como ressalta Lara (2011, p. 79) "[...] Poucos esforços foram feitos no sentido de minimizar as condições de sofrimento no trabalho; em contrapartida, muito se pensou no avanço da produtividade do capital".

Especificamente, as políticas sociais brasileiras, e entre elas a Previdência Social, desde a década de 1990, vem sofrendo um processo de desmonte e contrarreformas, pautadas em um discurso ideológico de déficit e recuperação da economia. No entanto, o estudo demonstra que se trata de uma ação, parte de um projeto capitalista mundial. Enfrentar apenas o fenômeno localizado em sua aparência, não se apresenta de forma suficiente, é necessário compreender as bases estruturais e direcioná-las aos processos de lutas. 
Neste sentido, este estudo não se propõe a buscar respostas, mas realizar críticas que possam subsidiar estratégias. A denúncia é de que nesta sociabilidade a busca pelo lucro se sobressai à reprodução da vida humana. E, portanto, é preciso a compreensão dos trabalhadores que a luta pela garantia ao direito previdenciário é um processo para garantia da vida humana nos limites desta sociabilidade, entretanto, não altera a relação capital $x$ trabalho, não elimina o processo de exploração, estruturante do modo de produção capitalista.

O atual contexto nos impõe que as lutas não podem ser restritas em defesa das políticas sociais que cumprem um papel importante, tanto para manter a força de trabalho, como garantir a reprodução do capital. Entretanto, torna-se necessário reafirmar que o horizonte é a superação de toda e qualquer forma de exploração, portanto, desta sociabilidade.

\section{REFERÊNCIAS}

ASSOCIAÇÃO NACIONAL DOS AUDITORES-FISCAIS DA RECEITA FEDERAL DO BRASIL (ANFIP); FUNDAÇÃO ANFIP DE ESTUDOS TRIBUTÁRIOS E DA SEGURIDADE SOCIAL. Análise da Seguridade Social 2019. Brasília (DF): ANFIP, 2020.

ANTUNES, Ricardo. Coronavírus: o trabalho sob fogo Cruzado. São Paulo: Boitempo, 2020.

AUDITORIA CIDADÃ. Gráficos 2011- 2019. Disponível:

https://auditoriacidada.org.br/conteudo/graficos-de-pizza-do-orcamento-geral-da-uniaoexecutado-2011-2018/. Acesso em: 18 FEV 2020.

BARROS, Alexandre. Desemprego chega a 14,7\% no primeiro trimestre, maior desde 2012. Estatísticas Sociais. 27 MAI 2021. Disponível em:

https://agenciadenoticias.ibge.gov.br/agencia-noticias/2012-agencia-denoticias/noticias/30793-desemprego-chega-a-14-7-no-primeiro-trimestre-maior-desde-2012e-atinge-14-8-milhoes-de-pessoas. Acesso em: 23 JUN 2021.

BEHRING, Elaine. Brasil em contra-reforma: a desestruturação do estado e perda de direitos desestruturação do estado e perda de direitos. São Paulo: Cortez, 2003

BRASIL. Ministério da Economia. Secretaria de Políticas de Previdência Social. Coordenação Geral de Estatística, Demografia e Atuária. Boletim Estatístico da Previdência Social, maio 2020.

CARTAXO, Ana Maria Baima. Estratégias de Sobrevivência: a previdência e o serviço Social. 2. ed. São Paulo: Cortez, 2008.

CORONAVÍRUS/ BRASIL. Painel Coronavírus. Disponível em: https://covid.saude.gov.br/. Acesso em: 23 jun. 2021.

DALL’AGNOL, Laísa. Auxílio emergencial vai pagar parcelas de $\mathrm{R} \$ 300$ a $\mathrm{R} \$ 4.800$. Folha de São Paulo, São Paulo, 3 nov. 2020. Disponível em: 
https://agora.folha.uol.com.br/grana/2020/11/auxilio-emergencial-vai-pagar-parcelas-de-r300-a-r-4800.shtml. Acesso em: 2 FEV 2021. Disponível apenas para assinantes.

FAVARO, Neide de Almeida Lança Galvão. Pedagogia histórico-crítica e sua estratégia política: fundamentos e limites. Maceió: Coletivos Veredas, 2017.

FATORELI, Maria Lucia; ÁVILA, Rodrigo; MULLER, Rafael. Gastos com a dívida pública cresceram 33\% em 2020. Brasília (DF): Auditoria Cidadã da Dívida, 2020. Disponível em: https://auditoriacidada.org.br/conteudo/gastos-com-a-divida-publica-cresceram-33-em2020/. Acesso em: 2 fev. 2021.

FEDERAÇÃO NACIONAL DOS SINDICATOS DE TRABALHADORES EM SAÚDE, TRABALHO, PREVIDÊNCIA E ASSISTÊNCIA SOCIAL. Presidente do INSS Culpabiliza Servidores (as) pelos Problemas Estruturais da Autarquia. Disponível em:

fenasps.org.br/2021/01/21/presidente-do-inss-culpabiliza-servidoresas-pelos-problemasestruturais-da-autarquia/. Brasília (DF), 31 jan. 2021. Acesso em: 9 fev. 2021.

GENTIL, Denise Lobato. Dominância financeira e o desmonte do sistema público de previdência social no Brasil. In: CASTRO, Jorge Abrahão de. POCHMANN, Marcio. Brasil: Estado social contra a barbárie. São Paulo: Fundação Perseu Abramo, 2020.

GENTIL, Denise Lobato. A falácia dos argumentos em defesa da reforma. Le Monde Diplomatique Brasil, Edição 141, 2 abr. 2019. Disponível: https://diplomatique.org.br/afalacia-dos-argumentos-em-defesa-da-reforma/. Acesso em: 12 fev. 2020.

GRANEMANN, Sara. Políticas Sociais e Financeirização dos Direitos ao Trabalho. In: Revista Em Pauta, n. 20, p. 56-68, 2007.

GRUPO BANCO MUNDIAL. Um ajuste justo: Análise da eficiência e equidade do gasto público no Brasil: Volume I: sintéticos (português). Washington, DC: Grupo do Banco Mundial. Disponível em:

https://www.worldbank.org/pt/country/brazil/publication/brazil-expenditure-reviewreport. Acesso em 02 FEV 2021.

HARVEY, David. Política anticapitalista em tempos de coronavírus. Blog da Boitempo, São Paulo, 24 mar. 2020. Disponível em: https://blogdaboitempo.com.br/2020/03/24/davidharvey-politica-anticapitalista-em-tempos-de-coronavirus/. Acesso em: 20 fev. 2021.

INSS: Pente-fino cancela 261,3 mil benefícios em quatro meses. Veja, 4 dez. 2019. Disponível em: https://veja.abril.com.br/economia/inss-pente-fino-cancela-261-milbeneficios-em-quatro-meses/. Acesso em: $20 \mathrm{FEV} 2021$.

INSTITUTO BRASILEIRO DE GEOGRAFIA E ESTATÍSTICA (IBGE). Síntese de Indicadores Sociais - Uma Análise das Condições de Vida da População Brasileira. Estudos e Pesquisa, Informação Demográfica e Socioeconômica, Brasília (DF), n. 43, 2020.

LARA, Ricardo. Saúde do trabalhador: considerações a partir da crítica da economia política. R. Katál., Florianópolis, v. 14, n. 1, p. 78-85, jan./jun. 2011. 


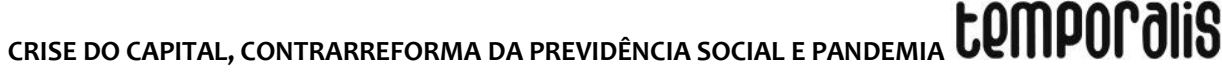

LARA, Ricardo; MARANHÃO, Cézar. Fundamentos do trabalho, "questão social" e Serviço Social. In: SOUZA, Edvânia Â. de Souza; SILVA, Maria Liduína de Oliveira e (orgs).

Trabalho, questão social e serviço social: a autofagia do capital. São Paulo: Cortez, 2019. p. 37-60.

LDO é sancionada com vetos a dispositivos que proibiam contingenciamentos. Senado Notícias, Brasília (DF), 4 jan. 2021. Disponível em:

https://www12.senado.leg.br/noticias/materias/2021/01/04/ldo-e-sancionada-com-vetos-adispositivos-que-proibiam-contingenciamentos. Acesso em: 02 FEV 2021.

LIMA, Eudes. A fome tem pressa. Revista Isto É, São Paulo, 5 fev. 2021. Disponível em: https://istoe.com.br/a-fome-tem-pressa/. Acesso em: 9 fev. 2021.

LORRAN, Tacio. INSS nega 4,46 milhões de benefícios em 2020, o maior número em 14 anos. Metrópoles, 10 fev. 2021. Disponível em :

https://www.metropoles.com/brasil/economia-br/inss-nega-446-milhoes-de-beneficiosem-2020-e-bate-novo-recorde. Acesso em: 18 FEV 2021.

LOURENÇO, Edvânia Ângela de Souza; LACAZ, Francisco Antonio de Castro; GOULART, Patrícia Martins. Crise do capital e o desmonte da Previdência Social no Brasil. Serviço Social e Sociedade, São Paulo, n. 130, p. 467-486, set./dez. 2017. Disponível:

http://www.scielo.br/pdf/sssoc/n130/0101-6628-sssoc-130-0467.pdf. Acesso em: 12 fev. 2010.

MAGNO, Alan. Saiba quando será paga a próxima parcela do auxílio emergencial de 2021. Disponível em:https://www.opovo.com.br/noticias/economia/2021/06/24/pagamentoproxima-parcela-auxilio-emergencial-2021-data-consulta-cpf.htmlm. Acesso em:24 JUN 2021.

MANDEL, Ernest. $O$ capitalismo tardio. São Paulo: Abril Cultural, 1982

MARX, KARL. O capital: crítica da economia política: livro I: o processo de produção do capital. 2 ed. São Paulo: Boitempo, 2017.

MESZÁROS, István. A crise estrutural do capital. São Paulo: Boitempo Editora, 2013.

MOTA, Ana Elizabete; TAVARES, Maria Augusta. Trabalho e expropriações contemporâneas. In: MOTA, Ana Elizabete; AMARAL, Angela (org.). Cenários, contradições e pelejas do serviço social brasileiro. São Paulo: Cortez Editora, 2016, p. 229254 .

NETTO, José Paulo. BRAZ, Marcelo. Economia Política: uma introdução crítica. 8. ed. São Paulo: Cortez, 2012.

OXFAM. O Vírus da Desigualdade. Relatório da Oxfam, jan. 2021. Oxfam GB para Oxfam Internacional. 
OXFAM. O vírus da fome: como o coronavírus está aumentando a fome em um mundo faminto. Comunicado de Imprensa OXFAM Brasil, 8 jul. 2020. Disponível: www.oxfam.org.br. Acesso: 2 fev. 2021.

PENTE-FINO: INSS cancelou 261 mil benefícios no país desde janeiro. UOL, Economia, São Paulo, 4 dez. 2019. Disponível em: -https://economia.uol.co $\mathrm{m} . \mathrm{br} /$ noticias/redacao/2019/12/04/pente-fino-inss.htm?cmpid=copiaecola. Acesso em: 2 fev. 2021.

SALVADOR, Evilásio da Silva. Fundo Público e Seguridade Social no Brasil. São Paulo: Cortez, 2010.

SALVADOR, Evilásio da Silva. O desmonte do financiamento da seguridade social em contexto de ajuste fiscal. Serviço Social e Sociedade, São Paulo, n. 130, p. 426-446, set./dez. 2017. Disponível: http://www.scielo.br/pdf/sssoc/n130/0101-6628-sssoc-1300426.pdf. Acesso em: 12 fev. 2020.

SALVADOR, Evilásio da Silva. Fundo público, crise e financeirização da previdência social. In: SALVADOR, Evilásio. BEHRING, Elaine. LIMA, Rita de Lourdes de. Crise do capital e fundo público: implicações para o trabalho, os direitos e a política social. São Paulo: Cortez, 2019.

SEGURIDADE SOCIAL E TRIBUTAÇÃO. Desconstrução do direito à previdência, Brasília (DF), ano 28, n. 38, p. 7-12, out. 2020.

SEM AUXÍLIO, R\$ 48 bi deixarão de circular entre os mais pobre. Época, Negócios. São Paulo, 31 jan. 2021. Disponível em:

https://epocanegocios.globo.com/Economia/noticia/2021/01/epoca-negocios-sem-auxilio-r48-bi-deixarao-de-circular-entre-os-mais-pobres.html. Acesso em: 9 fev. 2021.

SINDICATO DOS SERVIDORES E TRABALHADORES PÚBLICOS EM SAÚDE, PREVIDÊNCIA E ASSISTÊNCIA SOCIAL NO ESTADO DE SÃO PAULO (SINSPREV). Caos estrutural do INSS: uma bomba de efeito retardado prestes a explodir. São Paulo, 2 out. 2020. Disponível em: http://www.sinsprev.org.br/leitura.php?editoria=12072. Acesso em: 9 fev. 2021. 
Priscila Semzezem Trabalhou na análise e interpretação dos dados, redação do artigo e aprovação da versão a ser publicada.

Possui graduação em Serviço Social pelo Centro de Ensino Superior de Maringá (2008), Mestrado em Serviço Social e Política Social pela Universidade Estadual de Londrina (2012) e Doutorado em andamento em Serviço Social pela Universidade Federal de Santa Catarina. Atualmente é professora titular da Universidade Estadual do Paranál Campus Paranavaí. Pesquisadora no grupo de pesquisa GEPTESC - GRUPO DE ESTUDOS E PESQUISAS TRABALHO E EDUCAÇÃO NA SOCIABILIDADE DO CAPITAL, da UNESPAR- Universidade Estadual do Paraná/ Campus Paranavaí.

Ana Maria Baima Cartaxo Trabalhou na pesquisa, análise dos dados e redação do artigo .

Assistente Social , mestra e doutora pela Pontifícia Universidade Católica de São Paulo- PUCSP. Professora aposentada da Universidade Federal de Santa Catarina e professora colaboradora do Programa de PósGraduação em Serviço Social - PPGSS - UFSC. Integra o Núcleo de Estudos e Pesquisas Estado, Sociedade Civil e Políticas Públicas e Serviço Social- NESPP. Pesquisadora em Seguridade Social, particularmente na Política de Previdência Social e trabalho; e do exercício profissional no âmbito dessa política; com publicações nessa área. 